\title{
El poder en Moncloa: el jefe de Gabinete del presidente del Gobierno
}

\author{
The power in Moncloa: The Chief of Staff \\ of the President of the Government
}

\author{
ANTONIO GARRIDO \\ Universidad de Murcia \\ M. ANTONIA MARTÍNEZ \\ Universidad de Murcia
}

\section{Como citar/Citation}

Garrido, A. y Martínez, M. A. (2018). El poder en Moncloa: el jefe de Gabinete del presidente del Gobierno.

Revista Española de Ciencia Política, 48, 73-102. Doi:https://doi.org/10.21308/recp.48.03

\section{Resumen}

Este artículo presenta una investigación original basada en un conjunto de entrevistas que incluye a la práctica totalidad de los jefes del Gabinete del presidente del Gobierno, así como uno de los anteriores presidentes del Gobierno español. Se trata de comprender, desde este doble ángulo, los dos vértices de la relación entre el primer ministro y su principal asesor. El estudio aborda el perfil, el surgimiento y expansión de esta figura política y su evolución, a partir de algunos documentos inéditos de los archivos de Moncloa. Asimismo, muestra el doble poder de exclusión y conexión que ha acumulado el jefe del Gabinete y desarrolla un análisis comparativo del poder que han ejercido los distintos ocupantes del cargo desde la transición a la democracia.

Palabras clave: España, jefe de Gabinete de presidentes y primeros ministros, Presidencia institucional, Oficina Presidencial, núcleo ejecutivo, Gabinete, centro presidencial, Palacio de la Moncloa.

\begin{abstract}
This article presents an original research based on a set of interviews that includes both almost all the chiefs of staff of the office of the President of Government and one of the previous presidents of the Spanish Government. It tries to understand, from this double point of view, the two vertexes of the relationship between the prime minister and his main adviser.
\end{abstract}


The study deals with the profile, the emergence and expansion of this political figure and its evolution, with unpublished documents from Moncloa archives. It also shows the double power of exclusion and connection the chief of office has accumulated and it develops a comparative analysis of the power exercised by the various occupants of the post since the transition to democracy.

Keywords: Spain, presidents' and prime ministers' Chief of Staff, institutional presidency, Presidential Office, core executive, Cabinet, presidential center, Moncloa Palace.

\section{INTRODUCCIÓN: EL ESTUDIO DE LOS GABINETES Y LAS OFICINAS PRESIDENCIALES}

El descuido en la bibliografía sobre los órganos asesores de los presidentes y primeros ministros contrasta con el reconocimiento de la relevancia del papel del jefe de Gabinete, compartido tanto por académicos como por analistas políticos. En Alemania, The Economist se refería a Peter Almaier, el jefe de la Bundeskanzleramt, como el hombre más poderoso de Berlin; en el Reino Unido, el descalabro en las elecciones de Theresa May implicó el cese inmediato de sus jefes de Gabinete, Fiona Hill y Nick Timothy; en Estados Unidos, James Baker decía que el jefe de Gabinete es la segunda posición más poderosa en el Gobierno e, incluso, se ha afirmado que "el destino de cualquier Presidencia depende de esta posición poco comprendida» (Whipple, 2017: 11).

Por ello, el estudio de las oficinas presidenciales está recibiendo una especial atención en los últimos años (Inácio y Llanos, 2015; Lanzaro, 2016, 2018; Rhodes y Tiernan, 2014a, 2014b; Tiernan y Pfiffner, 2014; Truswell y Atkinson, 2011). En otros países, los jefes del Gabinete han estado muy presentes en la doctrina, especialmente el staff de la Casa Blanca (Cohen et al., 2012, 2016; Pfiffner, 1993, 2011; Sullivan, 2004; Virgala, 1994; Whipple, 2017). En España, sin embargo, este interés ha sido menor y los escasos estudios publicados sobre el Gabinete, con carácter general, han sido de tipo jurídico o sociológico (Olías, 1994; Ortega, 1991; Santolaya, 1991; Prats y Villoria, 2011) o permanecen inéditos (Molina, 1998) o se centran en el proceso de "presidencialización» del Gobierno (Heywood y Molina, 1997, 2000; Van Biezen y Hopkin, 2005).

La escasa atención al Gabinete del presidente del Gobierno, uno de los órganos más relevantes del core executive, el núcleo directivo del conjunto de estructuras y organizaciones que integran los distintos elementos del Gobierno, no se corresponde con su importancia política (Rhodes y Tiernan, 2013). Y este déficit es una constante en los más variados y diversos enfoques de los estudios sobre el Ejecutivo, ya sea el asymmetric power model, con su perspectiva segmentada y asimétrica sobre los órganos que lo forman, o el resource-dependence approach, con su énfasis en los juegos de intercambio de recursos entre agencias gubernamentales, o en la literatura sobre "presidencialización» del core executive, desarrollada en el Reino Unido, Alemania, Francia, Japón, 
Australia, etc. Todo ello, pese al reconocimiento de que el Gabinete del presidente del Gobierno es un elemento esencial del "very powerful political core of the executive» (Molina et al., 2018: 33).

Para paliar este déficit, el artículo presenta un análisis de la figura institucional de los jefes de Gabinete españoles, realizado a partir de entrevistas que abarcan a la mayoría de ellos e incluye a uno de los presidentes del Gobierno. En concreto, este estudio pretende contrastar dos hipótesis específicas, cuyo fundamento es el progresivo proceso de presidencialización del Gobierno en España al que hace referencia gran parte de la bibliografía, al destacar también el crecimiento del poder de los principales asesores del presidente; entre ellos, principalmente, el director del Gabinete. Estas hipótesis pueden formularse en los siguientes términos:

a) Hipótesis de la centralidad. El jefe de Gabinete ha ido aumentando su centralidad en el entorno presidencial a medida que su figura se ha institucionalizado y tanto sus competencias como su poder de influencia se han ampliado.

b) Hipótesis de la tradición partidista. El jefe de Gabinete ha tenido vínculos más estrechos con el presidente en función del partido en el Gobierno y sus tradiciones sobre el funcionamiento del entorno o «centro presidencial».

Ambas hipótesis serán contrastadas con la metodología del análisis de redes sociales (ARS), que se ha mostrado muy útil para el estudio y comprobación empírica de la estructura de las redes sociales de los Gobiernos. La dimensión de la centralidad del jefe del Gabinete en el complejo de Moncloa será sometida a un análisis empírico a través de distintos indicadores locales de centralidad y clustering, y especialmente la centralidad de intermediación (betweenness centrality). La dimensión partidista será objeto de medición a partir de distintos índices típicos del análisis reticular, radiales y mediales, como la centralidad de relevancia. Asimismo, el presente estudio desarrolla un estudio más amplio del contexto en el que opera el director del Gabinete, analizando el nivel de densidad y cohesión de la red gubernamental de Moncloa según las distintas presidencias, a partir de distintas medidas globales a nivel de red.

Con este propósito, el artículo se divide en cuatro apartados. Primero, esbozamos el perfil de los jefes de Gabinete, tanto personal como político, a partir de un análisis de los diez jefes de Gabinete que han desempeñado el cargo en España, que constituyen el conjunto de los casos observados. El tercer apartado trata sobre la construcción del poder político de estos cargos, su estilo de liderazgo y su visibilidad pública. La cuarta sección se dedica a mostrar su papel como gatekeeper, ejerciendo como filtro del acceso al presidente. En el siguiente epígrafe se desarrolla una tipología del poder y la centralidad de los jefes de Gabinete en la red gubernamental. Estas dos secciones abordan los dos principales poderes, de iure y de facto, de los jefes de Gabinete: su poder de exclusión, esto es, su faceta de gatekeepers o "guardianes de Moncloa»; y su poder de conexión, un concepto próximo a lo que los anglosajones denominan brokering power. Se concluye con unas breves consideraciones finales. 


\section{EL PERFIL POLÍTICO DEL JEFE DE GABINETE}

El perfil político de los jefes de Gabinete del gobierno espańol presenta ciertas pautas comunes. Primero, excepto la jefa de Gabinete del presidente Suárez, Carmen Díez, todos han sido hombres. Y lo han sido también todos los directores adjuntos, con la excepción de Cristina Ysasi. No son una excepción en el ámbito comparado, ya que son escasas las mujeres en estos puestos en Estados Unidos y en Europa, salvo en Francia - Mignon con Sarzozy y Hubac con Hollande-, Hill con Theresa May en el Reino Unido, o Boschi con Gentiloni, en Italia. Solo unos pocos ejemplos en la igualitaria Europa y ninguno en la Cancillería alemana o en la Casa Blanca. Una explicación posible es que los presidentes «que quieren o necesitan fuertes jefes de staff, están inclinados a tener hombres» debido a "prejuicios culturales» (Whipple, 2017: 278). Hay también coincidencia en la edad de acceso al cargo, próxima a la media de los 42,8 años, con escasas excepciones, como Galdón, que fue nombrado con 31 ańos o Serrano, quien, en su segundo periodo, ya alcanzaba los 54 años; y han sido más jóvenes que sus jefes, con las excepciones de Dorado o Serrano. Hay una mayor diversidad en su procedencia profesional, aunque la mayoría han sido juristas (Aza, Serrano, Moragas, Ayllón) y economistas (Galdón y Zabalza).

Pero, además de estos rasgos de carácter sociológico, también comparten algunos de carácter profesional. Por ejemplo, la experiencia política previa antes de su acceso al puesto: Alberto Aza, diplomático de carrera, había ocupado diversos cargos; Eugenio Galdón había sido director del Gabinete Técnico de la Vicepresidencia del Gobierno; Antoni Zabalza había ejercido como Secretario de Estado de Hacienda; José Enrique Serrano había sido secretario general de la Vicepresidencia y subdirector del Gabinete; Carlos Aragonés había sido jefe de Gabinete de Aznar en su etapa de Castilla y León; Jorge Moragas había trabajado en el Departamento de Protocolo de la Presidencia del Gobierno y como jefe de Gabinete del Secretario General de la Presidencia con Aznar; José Luis Ayllón ha sido secretario de Estado de Relaciones con las Cortes con Rajoy, y con Aznar asesor en el Gabinete; finalmente, Iván Redondo fue jefe de Gabinete del presidente extremeño, José Antonio Monago, y tenía una cierta experiencia política como consultor y en la dirección de campañas electorales, especialmente de ámbito regional o autonómico.

La experiencia en puestos previos similares, pero en otros niveles de gobierno, como Carlos Aragonés o Iván Redondo, es también frecuente en Alemania: Steinmeier con Schröder, primero como director del Gabinete en el Gobierno del Länder de Baja Sajonia y luego en la Cancillería alemana; De Maizière como jefe de staffen el Länder de Mecklemburgo-Pomerania y Sajonia, antes de desempeñar el mismo puesto a nivel federal con Merkel, etc. Lo mismo sucede en Estados Unidos: Obama y Trump han designado a políticos muy expertos en el funcionamiento de Washington como Rahm Emanuel o Reince Preibus (Whipple, 2017: 257-263).

También es habitual que el jefe de Gabinete haya acompañado en su trayectoria política al presidente en su etapa como líder de la oposición o como ministro, como 
Aragonés con Aznar, Moragas con Rajoy y, en un periodo mucho más breve, Redondo con Sánchez o, en el ámbito comparado, Steinmeier con Schröder, Mignon con Sarkozy, Powell con Blair, Llewellyn con Cameron, Timothy con Theresa May, etc. Menos frecuente es repetir en el cargo con distintos presidentes, como José Enrique Serrano, siguiendo la estela de James Baker, que sirvió con Reagan y con Bush. Esto es más probable, lógicamente, en aquellos sistemas políticos en los que los mismos dirigentes han vuelto a ocupar el puesto de primer ministro tras un periodo fuera del Gobierno, como en el caso italiano: Franco Evangelisti con Andreotti, Angelo Salizzoni con Aldo Moro, Gianni Letta con Berlusconi, etc.

En cuanto a su perfil político-administrativo, los jefes de Gabinete españoles han sido, primordialmente, políticos y no funcionarios. No olvidemos que, en el caso del Reino Unido, Blair encontró una fuerte oposición para crear un cargo de este tipo y nombrar para el mismo a su estrecho colaborador Jonathan Powell, debido a las fuertes resistencias del Civil Service británico y a la frontal oposición de Robin Butler, el secretario del Gabinete (Blair, 2010: 16-19; Powell, 2011: 80). Tal vez por una cierta inercia burocrática, también en España los primeros presidentes optaron por un jefe de Gabinete más «funcionarial», próximo al modelo inglés (Calvo Sotelo, 1990: 175-177): Alberto Aza era diplomático de carrera, subdirector de la Oficina de Información Diplomática; Eugenio Galdón era economista del Estado y había ocupado diversos cargos en la Administración pública. En cambio, a partir de González, los jefes del Gabinete han tenido un perfil nítidamente político y han procedido de fuera de la Administración pública: Roberto Dorado era un militante del PSOE que, trabajando en la empresa familiar, había tenido un papel destacado en la reorganización del PSOE bajo el franquismo; Carlos Aragonés era militante del Partido Popular, miembro de su Comité Ejecutivo Nacional, etc. (tabla 1).

En España, con la excepción de Aza, Galdón, Zabalza y Moragas, la mayor parte de los jefes del Gabinete han sido políticos en activo, aunque de bajo perfil, y se diferencian en este aspecto, por ejemplo, de los jefes de staff de la Casa Blanca o de la Cancillería Federal alemana, por lo que España se aleja de la tradición política de los Gobiernos de nuestro entorno. En Estados Unidos, Dick Cheney fue secretario de Defensa y vicepresidente del país; Alexander Haig secretario de Estado; Donald Rumsfeld, secretario de Defensa; James Baker, secretario de Estado y del Tesoro; Rahm Emanuel, congresista y alcalde de Chicago, etc. En Alemania, Wolfgang Schäuble fue ministro del Interior y de Finanzas y, actualmente, ejerce como presidente del Bundestag, Ronald Pofalla había sido diputado y portavoz del grupo parlamentario de la CDU, etc.

Algunos desarrollaron después su carrera política como diputados (Aragonés o Serrano), aunque los funcionarios, como Aza y Moragas, tras abandonar el cargo han regresado a la carrera diplomática o han ejercido funciones similares en otras altas instituciones del Estado. Los directores con un perfil más «economicista», por su parte, han continuado su carrera profesional en la empresa privada (Galdón y Zabalza) o pública (Dorado). 


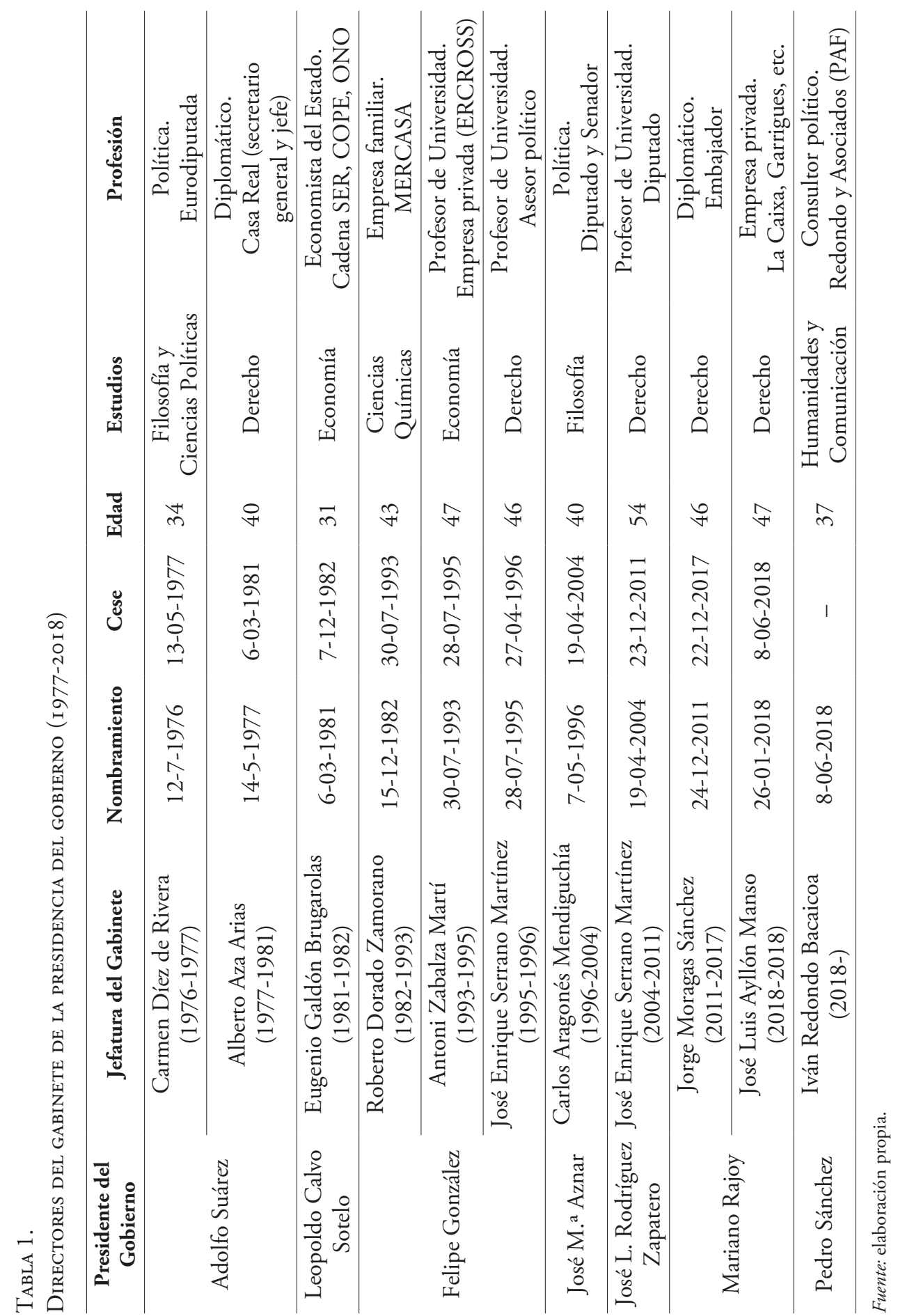




\section{LA CONSTRUCCIÓN INSTITUCIONAL DEL JEFE DE GABINETE}

El habitual carácter reservado de los jefes de Gabinete, cuyos colaboradores son conocidos como los "fontaneros de Moncloa", ha generado su bajo perfil mediático. Entre las leyes no escritas está la que otorga un papel invisible al jefe del Gabinete, de forma que apenas han concedido entrevistas a los medios de comunicación. De acuerdo con Serrano, el Gabinete debe ser «invisible: ni tiene opinión propia ni tiene presencia en los medios [...]. Ni tan siquiera hay fotos, nosotros nunca queríamos que nos sacaran en las fotos [...]. No queríamos ser un problema para el Gobierno ni para el presidente». Incluso, ni siquiera suelen acompañar a los presidentes en sus viajes oficiales; al menos, en las etapas de Aragonés y Serrano [Aragonés; Serrano]. En los viajes nacionales, el presidente solía ir acompañado por el subdirector, y en los internacionales por el director del Departamento de Internacional (y el secretario general de Presidencia en el segundo mandato de Zapatero), así como por el director de algún departamento económico, en el caso de desplazamientos con dicha finalidad.

Moragas ha sido una excepción a esta pauta, ya que siempre acompañaba al presidente. Su gran exposición pública ha generado un cierto debate en los medios sobre si es oportuno que el jefe del Gabinete permanezca en un segundo plano o bien ocupe un papel más protagonista. El criterio, hasta Moragas, era que el director del Gabinete no tenía opinión propia ni presencia en los medios; ni siquiera aparecía en las fotografías. Por su condición de persona muy próxima al presidente, además, era extremadamente cauto, ya que incluso en conversaciones informales sus interlocutores podían extraer la conclusión de que estaba expresando la opinión del propio presidente: «Se jugaba con un tema delicado, que era la autoridad del presidente [...]. Incluso en conversaciones informales había que tener cuidado, ya que se podía interpretar que se estaba expresando la opinión del presidente y se generaba un proceso de rumores que interpretaban que lo que tú decías era lo que pensaba el presidente [...]. Y decían «en Moncloa piensan» o «en Moncloa están enfadados» [...]. Había que medir mucho las palabras; por eso, escuchábamos mucho y no hablábamos [...]. El Gabinete exige una autocontención muy importante, tanto hacia fuera como hacia dentro [...]. No puedes expresarte frívolamente» [Serrano]. Por eso, la «autocontención» hacia dentro y hacia fuera ha tendido a ser un principio irrenunciable para todos los directores [Elorriaga y Fernández Lasquetty], como bien comprendió Emmanuelle Mignon, jefa de Gabinete de Sarkozy, envuelta en numerosas polémicas por sus declaraciones a la prensa, que le condujeron a la dimisión.

Esta invisibilidad, a diferencia de sus homólogos en Estados Unidos, Alemania u otros países, quizá ha hecho pensar que su papel podía ser secundario. Sin embargo, el crecimiento de las funciones, competencias y poder de los jefes del Gabinete ha situado el foco en esta figura. En este proceso de ampliación progresiva de su poder hay parcelas de influencia, incluso de soft power, que ha ido arrebatando a otros actores políticos en un proceso paulatino de expansión de sus atribuciones y competencias. 


\section{Poder derivado de funciones formales}

El poder del jefe de Gabinete deriva del que le delega el presidente del Gobierno en el marco de su propia relación de confianza y ha sido construido como una disputa permanente con otras fuentes de poder institucional en el entorno presidencial.

La construcción de la figura institucional del jefe de Gabinete se forjó, en una primera fase, en relación con la del vicepresidente del Gobierno. El diseño del Gabinete en 1982 se adaptó a las necesidades de Alfonso Guerra, lo que generó dos debates entrecruzados: primero, si el Gabinete debía depender de la Vicepresidencia o del Ministerio de la Presidencia; segundo, si debían existir dos gabinetes, para el presidente y para el vicepresidente, o bien para el presidente y para el ministro de la Presidencia. El primer problema se resolvió descartando la opción de que el jefe del Gabinete estuviera bajo la órbita del Ministerio de la Presidencia. La segunda cuestión, sobre la duplicidad de gabinetes, se resolvió en favor del vicepresidente como un «superjefe del Gabinete». El origen de esta decisión se encuentra en el viaje que Roberto Dorado y Francisco Ramos hicieron en el otońo de 1982 a Francia y a Alemania para estudiar los gabinetes socialistas de Schmidt y de Mitterrand y proponer una estructura similar [Dorado]. Ambos, colaboradores de Guerra, tras estudiar estas experiencias justificaron en un informe confidencial el ascendiente del vicepresidente sobre el Gabinete, tanto por la experiencia española, que tendía a reproducir una cierta dualidad o diarquía en la cúspide del poder (Franco-Carrero, Suárez-Abril, González-Guerra), como por la aplicación del modelo francés, que suponía una estructura de «bipolaridad operativa», lo que permitiría al presidente «elevar al máximo el papel que le asigna la Constitución y proyectando una imagen de hombre de Estado» en un reparto de roles similar a la de la V República entre presidente y primer ministro (Gabinete de la Presidencia del Gobierno, s. f. [1982]: 9-14).

La situación de dependencia del vicepresidente continuó bajo Narcís Serra y solo comenzó a cambiar al final del mandato de González con Serrano, cuando quedó vacante la Vicepresidencia. Bajo el mismo presidente, por tanto, la capacidad de decisión del jefe del Gabinete varió a lo largo de tres etapas: una primera, con Guerra de vicepresidente y Dorado como jefe del Gabinete; una segunda, con Serra de vicepresidente y Zabalza de jefe de Gabinete; y una tercera, sin que hubiera vicepresidente y en la que el mismo Serrano ejercía como director del Gabinete con un contacto más directo con González [Serrano].

El giro hacia una total autonomía del jefe del Gabinete se consumó con Aznar, quien nombró a dos vicepresidentes. Este cambio tuvo consecuencias directas sobre el poder del jefe del Gabinete, al pasar a responder solo ante el presidente. De acuerdo con Aragonés, el Gabinete en la etapa de González tenía un problema, y era que no asesoraba al presidente, sino al vicepresidente; por eso, su director no tenía un acceso tan directo al presidente como en su propia experiencia con Aznar. Ello explica, en su opinión, el comportamiento de González: «Si un presidente no tiene asesores en su Gabinete o no los usa, entonces tiene que buscar asesoría fuera o buscar la asesoría de sus ministros» [Aragonés]. No obstante, la separación entre el staff de asesores del 
presidente y de los vicepresidentes en España, que comenzaron a disponer de sus propios jefes de Gabinete con Aznar, no ha podido impedir una situación de conflicto latente — con distintos desenlaces - entre el jefe del Gabinete y algunos poderosos vicepresidentes cuando han vuelto a ser únicos, como en los casos de Fernández de la Vega y Serrano o Sáenz de Santamaría y Moragas.

El poder del jefe del Gabinete también se ha afirmado frente al resto de órganos que componen el complejo de la Presidencia. El proceso se ha producido, especialmente, a costa de la Secretaría General de la Presidencia, a quien ha arrebatado el control de la agenda del presidente [Elorriaga], en parte por la concepción compartida, por el PP y el PSOE, de que este órgano lo que hace es agenda de temas y estrategia [Serrano]. Para algunos miembros del Gabinete de Aznar, el que la agenda dependa del Gabinete hace que este tenga una posición predominante. Desde Aznar, la agenda la controlaba el subdirector del Gabinete, ya que el presidente deseaba que la agenda tuviera una orientación estratégica [Aznar]. Esto obligaba a organizar actos acompasados con las decisiones del Consejo de Ministros, con el objetivo de publicitar determinadas propuestas [Fernández Lasquetty].

Lo mismo cabe señalar en el ámbito de los discursos de los distintos presidentes: en la etapa de González, «la mayoría de los discursos salían del Gabinete, pero luego la redacción última la hacía la secretaria general de Presidencia, Rosa Conde, porque González tenía una confianza personal y política muy fuerte con ella»; en cambio, después de González, los discursos los han elaborado los miembros del Gabinete [Serrano].

En algunos casos se han ido consolidado de forma permanente áreas determinadas que pasaban al control del Gabinete, como la seguridad nacional o la gestión de crisis [Serrano]. Incluso, tras la reestructuración de la Presidencia del Gobierno en julio de 2017, la misma Secretaría General de la Presidencia del Gobierno pasó a depender directamente del director del Gabinete (gráfico 1; Real Decreto 766/2017, de 28 de julio). Por eso, algunos analistas han llegado a afirmar que «las responsabilidades de la Secretaría han quedado reducidas al día de hoy a la gestión de Protocolo y la Seguridad del recinto de la Moncloa» y que «durante la actual legislatura, el presidente Rajoy ha concentrado las funciones más relevantes de la Secretaría en su Gabinete, y como consecuencia de ello la Secretaría General de la Presidencia es la más débil desde 1982» (Paniagua, 2018: 406-407).

No en todos los ámbitos la disputa por la construcción del poder del jefe de Gabinete ha sido tan exitosa. Un buen ejemplo es el surgimiento en el complejo de Moncloa de la Oficina Económica del Gobierno durante la presidencia de Aznar, que pretendía originalmente difundir un claro mensaje sobre la importancia de los temas económicos para el propio Gobierno (gráfico 1). De este modo, según Serrano, llegó a crearse una cierta bicefalia, una especie de «segundo jefe de Gabinete», ya que, al frente de la Oficina Económica, que era «novedosa respecto a la tradición de los gabinetes del PSOE», se encontraba un poderoso secretario de Estado, Miguel Sebastián, que controlaba los dos departamentos económicos: Economía y Política Social [Serrano]. El problema de la Oficina Económica es que José Barea y Miguel Sebastián, sus primeros directores con Aznar y Zapatero, tuvieron un perfil político alto y ello 


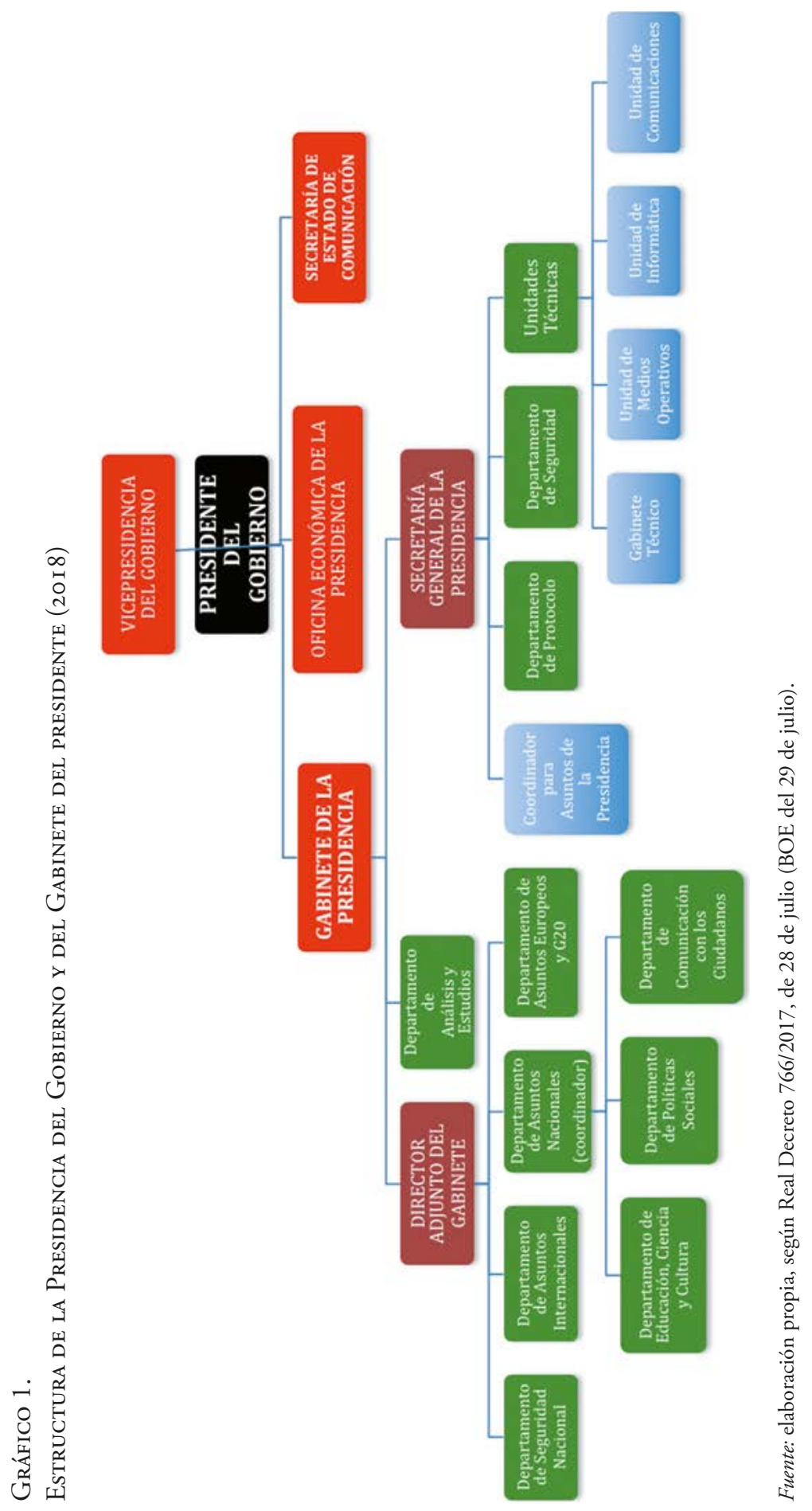

Revista Española de Ciencia Política. Núm. 48. Noviembre 2018, pp. 73-102 
creó distintos conflictos con los ministros de Economía y Hacienda. De ahí, el más bajo perfil político de sus sucesores (Baudilio Tomé, David Taguas o Javier Vallés), lo que propició una cierta devaluación de este órgano, continuada con la designación de Álvaro Nadal y Eva Valle en el Gobierno de Rajoy, y su desaparición en el nuevo Gabinete que ha anunciado Pedro Sánchez (Molina et al., 2018: 34).

En ningún caso, este órgano registró en su composición el perfil independiente que caracteriza al Consejo de Asesores Económicos del presidente en Estados Unidos, formado por expertos procedentes de las mejores universidades del país, entre los que se encuentran Premios Nobel, como Stiglitz, o prestigiosos economistas, como Greenspan o Bernanke, que han sido posteriormente presidentes de la Reserva Federal, ni reconocidos académicos como Feldstein o Furman (Harvard), Goolsbee (Chicago), (Princeton), etc. En su lugar, la Oficina Económica del presidente ha estado dominada en España por grupos vinculados a cada uno de sus directores: Miguel Sebastián y sus colaboradores en el Servicio de Estudios del BBVA (David Taguas, Carmelo Tajadura, Jorge Vázquez, etc.), o Álvaro Nadal (Eva Valle, Daniel Navía, etc.).

Otro ámbito en el que la expansión del poder del jefe de Gabinete no ha sido tan exitosa es la comunicación. Para algunos miembros del Gabinete, «en términos lógicos, la comunicación debe ser una parte del Gabinete [...]. ¿Cómo es que el que hace la agenda y prepara las intervenciones del presidente no hace la comunicación, como se hace en otros gabinetes?» [Elorriaga]. Esta cuestión ha implicado una disputa por el control de la comunicación del Ejecutivo, en la que el jefe del Gabinete, el jefe de prensa del presidente, el vicepresidente y el propio ministro portavoz, pugnan por hacerse con el control del mensaje del Gobierno. En la época de Aznar, estas eran competencias de los órganos que dominaban la comunicación, como indicó Aragonés, pero «el Gabinete tendía a tener su propio criterio y, si esa opinión estaba muy enfrentada con Comunicación, se generaba un conflicto en el que, finalmente, primaba la opinión del Gabinete» [Elorriaga]. En esta misma etapa, como seńaló Elorriaga, para estudiar otras experiencias, algunos miembros del Gabinete visitaron el Reino Unido y el problema era similar, ya que los directores de comunicación de Tony Blair, como Alistair Campbell o David Hill, tenían «una gran potencia política propia» que dificultaba su coordinación con el propio Gabinete, «pese a que, formalmente, la comunicación estaba integrada dentro del propio Gabinete» [Elorriaga]. Este problema se ha intentado resolver después de Aznar, tanto con Zapatero como con Rajoy, concentrando las funciones de vicepresidenta, ministra de la Presidencia y portavoz. Sin embargo, ambas vicepresidentas han acabado perdiendo esta competencia a favor de distintos portavoces gubernamentales.

Otros ámbitos de relevancia son las relaciones con las Cortes y la competencia sobre análisis demoscópicos. Por lo que respecta a las relaciones con las Cortes, suele haber una relación muy fluida entre el Gabinete y el grupo parlamentario para la preparación de las sesiones de control al Gobierno, las preguntas orales y los debates parlamentarios. En cuanto a la carencia de un departamento de diseño de encuestas propias, tanto Aragonés como Serrano explicaron, en parecidos términos, su ausencia: primero, por las limitaciones presupuestarias del Gabinete; y segundo, por la 
existencia de un organismo público (CIS) competente en la materia, lo que ha dificultado la justificación de un departamento demoscópico "no controlado o publicitado» [Aragonés; Serrano]. Aragonés, además, aludió a una tercera causa en el caso del PP: la existencia de una larga tradición de asesoría externa en esta materia que informaba directamente al presidente del Gobierno [Aragonés].

\section{Poder derivado de influencia (soft power)}

La construcción del poder del jefe de Gabinete también se ha desarrollado aumentando su influencia (soft power) sobre otros actores del Gobierno. Primero, este poder se ha construido en disputa con los ministros al tener que asumir un cierto rol de coordinación interministerial que, en algunos casos, ha generado tensiones institucionales dado que determinados ministros, que son dirigentes con un elevado perfil político, se resisten a esta labor de tutela, pues «hoy los ministerios, como es natural, ven con desconfianza al Gabinete del Presidente porque es alguien que trabaja sobre los mismos temas, que no tiene autoridad propia, pero que está muy cerca de la persona que tiene autoridad sobre ellos mismos» [Fernández Lasquetty]. Este fenómeno también está provocado por la mayor estabilidad del Gabinete respecto a los ministerios, ya que en estos suele haber más rotación (Müller-Rommel, 2008) [Elorriaga].

En la primera etapa de Dorado, el papel del Gabinete, según afirmaban públicamente algunos ministros, era asimilable al de un «comisariado» sobre el Gobierno, lo que generó tensiones institucionales. Según Dorado, el problema era que los ministerios querían «o ignorarte o fagocitarte y lograr el equilibrio era muy importante». Desde su punto de vista, "estos choques con los ministros eran inevitables», pero en algunos casos la tensión llegó hasta tal punto que consideró la opción de demandar ante los tribunales al diario El Pais por publicar informaciones que afirmaban que "puenteaba» a los ministros. Según Serrano, la relación entre el Gabinete y los ministros es "de desconfianza sin connotación negativa»; más bien, puede afirmarse que «los ministros tienen una relación de cautela con el Gabinete» y el jefe del Gabinete tiene que tener un gran cuidado para que «el ministro no se sienta puenteado pero tampoco desatendido». Pero entre 1982 y 1991, el Gabinete tendió más al control de la actividad ministerial, como el propio Dorado había recogido en su informe de 1982: «Los departamentos deben revisar y emitir informes sobre todos los proyectos o acciones que realicen los diferentes ministerios. Al mismo tiempo deben cuidar que estos se ajusten al programa sectorial correspondiente [...] pero si opina en contra de lo propuesto debe intentar que modifiquen la propuesta. Si no se consigue, transmitir al nivel superior acompañando su opinión fundamentada para que se dirima en ese escalón. Esto exige que los integrantes de los departamentos tengan una preparación técnica de primera categoría y un nivel político notable (especialmente, el director del Departamento)» (Gabinete de la Presidencia del Gobierno (s. f. [1982]: 20-21).

La disputa política y conceptual sobre qué debía primar —el control o la coordinación-, se reflejó durante toda la etapa del Gobierno de Felipe González. La 
interpretación centrada en el control ministerial giraba hacia la coordinación interministerial en un informe inédito de 1993 del Gabinete de la Presidencia del Gobierno, que subraya que «la relación del Gabinete con los ministerios es una cuestión fundamental», ya que a estos debe ofrecer su "capacidad para promover y empujar políticamente la ejecución de sus iniciativas, para mediar en los conflictos interministeriales y para allanar dificultades con la Presidencia, para transmitir la línea política del Gobierno, tanto en lo que afecte a sus iniciativas como con carácter más general, para coordinar actuaciones interministeriales y para, en algunos casos, asistirlos técnicamente» (Gabinete de la Presidencia del Gobierno, s. f. [1993]: 9-10).

Por otra parte, no hay que olvidar que determinados conflictos entre equipos ministeriales son frecuentes. Y la necesaria labor de mediación y arbitraje suele recaer en el jefe del Gabinete o en el ministro de la Presidencia, antes de ser ejercido en última instancia por el mismo presidente del Gobierno si las tensiones o disputas no se han podido resolver. Por eso, Serrano subrayó que el Gabinete no tiene como función «controlar o vigilar a cada uno de los ministerios o a cada uno de los ministros, sino contribuir a que el Gobierno se desempeñe como tal, como un Gobierno y no como una mera yuxtaposición de ministros». En la etapa de este jefe de Gabinete socialista, los asesores no hacían un seguimiento permanente y específico a cada ministerio, pues «nunca había concebido el Gabinete de la Presidencia como, por utilizar una expresión muy vieja, un comisariado político", sino como un órgano de coordinación y asesoramiento [Serrano]. José María Aznar también enfatizó la importancia de esta función al indicar que «la acción de gobierno no era una acción de ministerios aislados, sino una acción en conjunto». Además, matizó que el conflicto entre Gabinete y ministerios no «es tanto por visión diferente de las cosas como por ritmo, profundidad, ya que nosotros éramos muy partidarios de generar iniciativas y Moncloa era un elemento importante de presión continúa, de generar cosas, proyectos, pues los ministerios tienen mecanismos mucho más lentos y naturales de resistencia a muchas reformas» [Aznar].

Esta coordinación puede ser coyuntural, como la preparación de los debates parlamentarios del presidente del Gobierno o la elaboración de planes conjuntos, del tipo del Plan de Seguridad Ciudadana de 2002, que abarcan un paquete heterogéneo de medidas que implican a distintos ministerios, pues es difícil que este tipo de acciones pueda iniciarse en un único ministerio, por lo que es el jefe de Gabinete quien tiende a liderar los equipos para su diseño e implementación [Fernández Lasquetty]. También dicha coordinación suele revestir un carácter asimétrico, ya que la labor de coordinación con los ministerios no se realiza del mismo modo y con independencia del perfil del ministro, sino que se tiende a tutelar más la labor de aquellos que son más débiles políticamente y que carecen de una base autónoma de poder, o incluso de una base de relación propia, personal y directa con el presidente [Aragonés].

El proceso de la integración europea ha transformado los procesos de toma de decisiones dentro del core executive, lo que ha afectado al propio Gabinete (Colino y Molina, 2007: 147). En el área exterior, el desarrollo de relaciones con sus homólogos europeos también ha transformado y reforzado el rol del jefe del Gabinete (Colino y Molina, 2005: 346). Con Aragonés, por ejemplo, se tejieron redes para facilitar las 
relaciones entre presidentes, lo que llevó a la agenda pactada de Lisboa, la firma de artículos conjuntos por Blair y Aznar en los medios de comunicación, la cooperación estrecha para la preparación de la presidencia española de la UE, etc. Estas redes han sido también cuidadas en el periodo de Moragas gracias a sus estrechas relaciones con otros jefes de Gabinete como Llewellyn (Cameron), Frémont (Sarkozy) o Altmaier (Merkel), que permitieron un mejor posicionamiento de Rajoy entre sus pares europeos.

Su influencia se ha facilitado también por la presencia de miembros del Gabinete en los principales órganos colegiados, especialmente aquellos que realizan funciones de coordinación, como las comisiones delegadas del Gobierno y la Comisión de Secretarios de Estado y Subsecretarios o las distintas comisiones interministeriales. De hecho, una de las principales recomendaciones que recibió Aragonés de su predecesor fue la de que mantuviera la presencia del Gabinete en todas las comisiones delegadas y, especialmente, en la Comisión Delegada para Asuntos Económicos [Aragones; Fernández Lasquetty]. Muy importante es la presencia en la Comisión de Secretarios de Estado y Subsecretarios, ya que les permite conocer los intereses de cada ministro e informar al presidente si se detectan diferencias entre algunos sobre asuntos específicos [Fernández Lasquetty].

Por último, la construcción de la influencia del jefe de Gabinete ha sido también a costa del propio partido que sustenta al Gobierno, ya que al tener el partido que actuar como caja de resonancia del este último, el partido se convierte más en organizador que en coautor de las decisiones [Aragonés]. Pero esta relación depende de cada director de Gabinete: la relación entre este y el partido es más fluida si el jefe del Gabinete pertenece a la ejecutiva del partido, como en el caso de Aragonés o Moragas y Ayllón [Aragonés] y, cuando no sucede así, como con Serrano, para facilitar la comunicación se organizaban reuniones de coordinación, denominadas de "maitines», y comidas semanales con los responsables de los tres apoyos de la acción del Ejecutivo: el propio Gobierno (Fernández de la Vega), el grupo parlamentario (Rubalcaba) y el partido gubernamental (Blanco) [Serrano].

\section{EL «PODER DE EXCLUSIÓN": LOS JEFES DE GABINETE COMO GATEKEEPERS. "GET THE RIGHT PEOPLE IN THE ROOM"}

La función de gatekeeper de los jefes de Gabinete les permite controlar el acceso al presidente de otros colaboradores, cargos y representantes políticos. Es un típico poder de «exclusión» o «inclusión». En el ejercicio de este rol, la personalidad de cada uno de ellos y del propio presidente ha permitido que el acceso a este último sea más abierto, o bien más cerrado y controlado estrictamente por el jefe de Gabinete. En Canadá, por ejemplo, el modelo depende de la personalidad del primer ministro. Algunos directores del Gabinete han tenido un acceso exclusivo al jefe del Ejecutivo y solo ellos despachan con él, como Lalonde con Pierre Trudeau, mientras que otros, como Mulroney o Chrétien, han preferido un enfoque menos jerárquico, permitiendo a algunos consejeros sobrepasar al jefe de staffy despachar directamente con ellos. También en Australia, Hawke prefería un acceso más fácil de otros colaboradores, ya que consideraba 
muy importante que los jefes de Gabinete «nunca sean el único punto de contacto del primer ministro» (Rhodes y Tiernan, 2014b: 106). En el caso de España, observamos las mismas pautas de estos casos comparados: la etapa de Aragonés sería un ejemplo de un modelo de acceso más abierto, mientras que con Serrano o Moragas el acceso ha sido más restringido y limitado [Elorriaga; Fernández Lasquetty; Serrano].

Debido a este "poder de exclusión» como gatekeeper, se aconseja a los presidentes que nombren a «jefes fuertes», ya que débiles jefes de staff en Estados Unidos, como Hamilton Jordan con Carter o Mack McLarty con Clinton, han causado problemas a sus presidentes (Whipple, 2017: 298). No obstante, para el desempeño de este papel un buen equilibrio entre debilidad y fortaleza resulta más apropiado, ya que una fuerte personalidad puede interferir en sus funciones y cierta insensibilidad acaba por alienar a sus propios subordinados, generar conflictos con los miembros del Congreso y del partido y fomentar relaciones de hostilidad con la prensa, como en los casos de Adams-Eisenhower, Haldeman-Nixon, Reagan-Reagan- y Priebus-Trump, que dimitieron «tras caer en desgracia y habiendo causado un gran dańo político a sus presidentes» (Tiernan y Pfiffner, 2014: 20).

En el documento que sirvió para la construcción del Gabinete con González en 1982, ya se explicitaba esta función de gatekeeper, enumerando «quién tiene libre acceso telefónico total o quién parcial» al presidente (tabla 2): "Los no reseñados, salvo casos excepcionales, no se pueden comunicar directamente con él. El acceso parcial significa que hay que decir previamente que está ocupado y que se le llamará en cuanto se pueda. Quedando a discreción del director de Gabinete si se le llama o le telefonea él previamente para enterarse del asunto» (Gabinete de la Presidencia del Gobierno, s. f. [1982]: 27).

TABLA 2.

ACCESO LIBRE O DIRECTO Y ACCESO PARCIAL AL PRESIDENTE, SEGÚN LA DISCRECIONALIDAD DEL JEFE DEL GABinete (I982)

\begin{tabular}{|c|c|c|}
\hline & Acceso libre o directo & $\begin{array}{c}\text { Acceso parcial (a discrecionalidad } \\
\text { del jefe del Gabinete) }\end{array}$ \\
\hline $\begin{array}{c}\text { Asesores y } \\
\text { colaboradores }\end{array}$ & $\begin{array}{l}\text { Vicepresidente } \\
\text { Director Gabinete } \\
\text { Jefe Secretaría Particular } \\
\text { Subjefe Secretaría Particular } \\
\text { Responsable Secretaría Personal } \\
\text { Jefe Seguridad Personal } \\
\text { Familiares y amigos (señalados de } \\
\text { antemano) }\end{array}$ & $\begin{array}{l}\text { Ministros } \\
\text { Secretarios de Estado } \\
\text { Directores Departamentos Gabinete } \\
\text { Jefe Oficina Prensa Gabinete }\end{array}$ \\
\hline $\begin{array}{l}\text { Representantes } \\
\text { institucionales }\end{array}$ & $\begin{array}{l}\text { Jefe del Estado } \\
\text { Presidente Cortes } \\
\text { Presidente Senado } \\
\text { Presidentes o Jefes de Gobierno } \\
\text { extranjeros }\end{array}$ & $\begin{array}{l}\text { Alcaldes capitales y presidentes } \\
\text { Diputación } \\
\text { Presidentes CC. AA. } \\
\text { Presidentes Parlamentos } \\
\text { autonómicos }\end{array}$ \\
\hline
\end{tabular}




\begin{tabular}{|c|c|c|}
\hline & Acceso libre o directo & $\begin{array}{l}\text { Acceso parcial (a discrecionalidad } \\
\text { del jefe del Gabinete) }\end{array}$ \\
\hline $\begin{array}{c}\text { Otros } \\
\text { representantes } \\
\text { políticos }\end{array}$ & $\begin{array}{l}\text { Presidente PSOE } \\
\text { Secretario General UGT }\end{array}$ & $\begin{array}{l}\text { Secretarios Ejecutiva Federal PSOE } \\
\text { Secretarios generales regionales } \\
\text { Portavoz Grupo Parlamentario } \\
\text { Secretario general partidos y } \\
\text { sindicatos } \\
\text { Secretarios generales partidos de la } \\
\text { Internacional Socialista } \\
\text { Presidente CEOE } \\
\text { Presidente de la Asociación de la } \\
\text { Banca } \\
\text { Presidente de la Conferencia } \\
\text { Episcopal }\end{array}$ \\
\hline
\end{tabular}

Fuente: elaboración propia a partir de Gabinete de la Presidencia del Gobierno (s. f. [1982]: 27).

Una segunda tarea como gatekeeper es el reclutamiento de los distintos asesores y colaboradores del presidente en el Gabinete. Se trata de una importante labor de filtro que en la Casa Blanca suele conocerse como "get the right people in the room» (Rhodes y Tiernan, 2014b: 105-108). Esta tarea se ha convertido en la principal función del director de Gabinete como jefe de personal porque, por ejemplo, ni Aznar ni Zapatero conocían de forma previa a la mayor parte de los asesores que formaban su Gabinete. Los presidentes tomaban decisiones de tipo más estructural y tendían a marcar los criterios básicos al director: así, fue decisión de Aznar reducir la estructura y fusionar distintos departamentos porque siguió el criterio de mantener «un Gabinete sustancialmente más reducido que el anterior», pues siempre tuvo «la idea de no tener gabinetes muy extensos [...], sino gabinetes concentrados en los temas y con personas muy seleccionadas» [Aznar]. Aznar y Aragonés confirmaron en sendas entrevistas que la fusión de áreas fue decisión del presidente [Aznar; Aragonés]. En cambio, la selección del personal asesor suele ser una tarea más típica del director del Gabinete. Así Aznar, por ejemplo, tenía una relación previa de trabajo y confianza con los directores de Departamento, pero no conocía a la mayoría de los asesores [Aznar]. La situación con Zapatero era similar, pese a que puntualmente incorporó a algunos colaboradores procedentes de su entorno de León [Serrano], que es una práctica habitual en Estados Unidos: Carter, de su estado, Georgia, conocidos despectivamente como «los cacahueteros»; Obama, por su parte, nombró a varios conocidos de Chicago, que eran denominados como el «clan» o la «mafia de Chicago» (Cohen et al., 2012; Whipple, 2017: 263), etc.

En esta segunda acepción de gatekeepers como reclutadores, destaca el proceso de selección de sus principales colaboradores: el subdirector o director adjunto del Gabinete y su propio jefe de Gabinete (tabla 3). El director adjunto, un cargo cada vez más relevante por sus competencias en materias como la seguridad nacional y la gestión de crisis, suele ser un dirigente político de su confianza (gráfico 1). Por ello, 


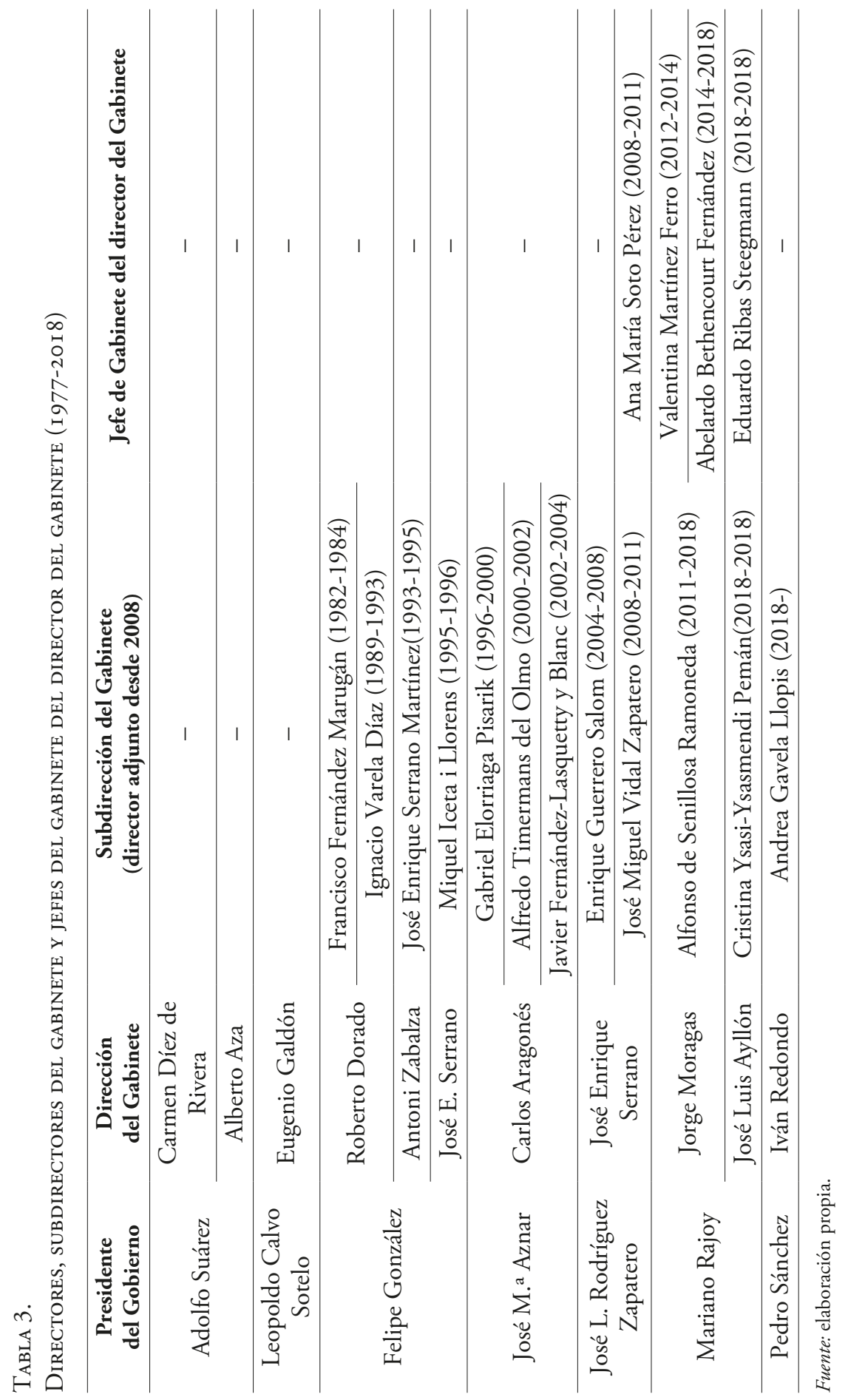


cuando es cesado el jefe de Gabinete también es cesado el subdirector: tras la marcha de Dorado fue sustituido su director adjunto, Fernández Marugán; Varela fue relevado tras la salida de Moncloa de Zabalza; Senillosa abandonó el Gabinete tras la salida de Moragas... En general, la estabilidad del director adjunto es una de sus características principales, ya que permanece en el cargo durante todo el mandato del jefe de Gabinete. Solo en las largas etapas de Carlos Aragonés o de Serrano se produjeron cambios en esta posición debidos a distintos ascensos. La sustitución del subdirector tampoco suele suponer ninguna fisura en el equipo dirigente, dada la costumbre de que alguno de los directores de los departamentos asuma dicho cargo: cuando fueron nombrados como subdirectores, Ignacio Varela dirigía el Departamento de Análisis, Alfredo Timermans era director del Departamento de Internacional y Javier Fernández-Lasquetty era el responsable de Institucional; del mismo modo, tras la salida de Enrique Guerrero o Senillosa como subdirectores, el puesto fue ocupado por José Miguel Vidal Zapatero y Cristina Ysasi-Ysasmendi, que ejercían como directores del Departamento de Institucional y de Asuntos Nacionales, respectivamente.

En segundo lugar, la aparición de la figura de director de Gabinete del jefe del Gabinete, que puede parecer una redundancia, se produjo en 2008 con el nombramiento de Ana María Soto como jefa de staff de José Enrique Serrano. Todos los ocupantes del cargo han sido estrechos colaboradores del jefe de Gabinete: Valentina Martínez y Abelardo Bethencourt, de Moragas; y Eduardo Ribas, de Ayllón.

Pero el control del director del Gabinete va más allá del proceso de selección, ya que el trabajo de los asesores también atraviesa su filtro antes de llegar al presidente. Desde «Roberto Dorado se instauró un sistema de notas informativas e informes que van siempre firmadas por el asesor, el director del departamento correspondiente y el jefe del Gabinete, que es el único que tiene el privilegio de decidir si se manda o no al presidente» y eso creó unas pautas de actuación continuadas por el PP [Dorado; Aragonés]. Así se ha consolidado la tradición de que el director es el principal gatekeeper de los informes y actos de sus colaboradores, tanto las Carpetas del Consejo de Ministros como las Notas Informativas y los Informes Monográficos, que solo llegan al presidente si el director del Gabinete se las traslada (Ortega, 1991: 241).

\section{EL «PODER DE CONEXIÓN»: CENTRALIDAD DEL JEFE DE GABINETE EN LA RED GUBERNAMENTAL DE MONCLOA}

En la política moderna, el poder no se concibe solo como poder de «exclusión» (o «inclusión»), sino también como un poder de "conexión», según la clásica concepción del poder reticular de Foucault o los más recientes enfoques de las relaciones internacionales (Slaughter, 2017). Desde este prisma, el nivel de poder del jefe de Gabinete dependerá de su grado de centralidad en la red gubernamental y de sus recursos relacionales, cuestiones que pueden ser analizadas mediante el empleo de diferentes índices de cohesión y centralización del entorno presidencial, recogidos en distintas 
medidas de densidad, modularidad, centralidad o conectividad (Hanneman y Riddle, 2005; Kadushin, 2012; Prell, 2012) en las tablas 4 y 5.

Por un lado, el grado de cohesión de la red interna de la Presidencia del Gobierno, medida a través de un índice de modularidad, permite conocer el nivel de unión interna de los gabinetes y jerarquizarlos en función de su aproximación al ideal de una comunidad bien integrada y unificada o, en cambio, diversificada en diferentes subcomunidades políticas. Información complementaria proporcionan tanto el índice de densidad de la red, que mide el número de vínculos en relación al de los potencialmente existentes, como el promedio de vínculos de cada nodo o actor de la red.

Un segundo aspecto que destacar es el grado de centralización y de conexión alrededor de un punto focal del entorno presidencial, medido a través de un índice de conectividad de la red, que refleja la proporción de actores conectados al hub o conector principal y permite especificar el grado de concentración del poder en un solo actor, ya sea el presidente o el vicepresidente o el mismo director del Gabinete.

TABLA 4.

Medidas de densidad, cohesión y centralización de la Presidencia del Gobierno (1982-2018)

\begin{tabular}{lcccc}
\hline \multicolumn{1}{c}{ Presidente } & $\begin{array}{c}\text { Índice de } \\
\text { densidad }\end{array}$ & $\begin{array}{c}\text { Índice de } \\
\text { modularidad }\end{array}$ & $\begin{array}{c}\text { Índice de } \\
\text { grado medio }\end{array}$ & $\begin{array}{c}\text { Índice de } \\
\text { conectividad }\end{array}$ \\
\hline González/Guerra & 0,137 & 0,305 & 3,550 & 0,780 \\
\hline González/Serra & 0,108 & 0,472 & 3,226 & 0,566 \\
\hline Aznar & 0,152 & 0,261 & 5,459 & 0,602 \\
\hline Zapatero & 0,079 & 0,540 & 3,143 & 0,353 \\
\hline Rajoy & 0,076 & 0,467 & 2,670 & 0,586 \\
\hline Media & 0,110 & 0,409 & 3,609 & 0,577 \\
\hline
\end{tabular}

Fuente: gráfica Gephi.

Estas medidas permiten mostrar diferencias, conceptual y políticamente, entre gabinetes formados por equipos con un núcleo bien definido y cohesionado (Dorado, Aragonés y Moragas), y cuyos miembros han trabajado juntos antes, y gabinetes poco cohesionados y compuestos por grupos heterogéneos de asesores con una escasa relación de trabajo previa entre sí (Dorado — bajo Serra— - y Serrano). También, según estos diferentes indicadores, podemos contrastar las dos hipótesis de partida de la investigación:

H1: Hipótesis de la centralidad. Los datos confirman que se ha producido un aumento progresivo de la influencia de los jefes de Gabinete en el entorno presidencial: según el índice de centralidad de intermediación - betweenness centrality-. Dorado presenta las tasas más bajas (21.5) y Serrano (204.23) y Moragas (458.58) las más altas. Esto ha convertido al jefe del Gabinete en un actor clave, debido a su condición de intermediario o 
punto intermedio, dada su participación en un mayor número de contactos entre los distintos actores gubernamentales. Algo similar sucede en Estados Unidos y, según Niall Ferguson (2018: 291-292), ya en la presidencia de Nixon solo Kissinger tenía una «centralidad de intermediación» mayor que el jefe del Gabinete, Haldeman, que superaba en este índice, incluso, al vicepresidente Ford o al consejero presidencial John Dean. No hay que olvidar que la centralidad de intermediación supone brokering power, que a su vez genera «poder de negociación» (Slaughter, 2017: 169).

H2: Hipótesis de la tradición partidista. Los indicadores derivados de las técnicas de ARS confirman, asimismo, que el jefe del Gabinete ha tenido vínculos más estrechos con el presidente en función del partido en el Gobierno y sus tradiciones sobre el funcionamiento del entorno o "centro presidencial»: los directores de Gabinete del PP han tenido un vínculo de confianza más estrecho con sus respectivos presidentes que sus homólogos socialistas, lo que reforzó su capacidad de influencia. Eso explica que en todas las medidas del análisis reticular, radiales y mediales, los índices más altos correspondan a Aragonés y Moragas. Solo Dorado presenta algunos índices de centralidad similares, con Guerra en la Vicepresidencia. Tanto Serrano — con Zapatero(0.642) como Dorado y Zabalza — bajo Serra - $(0.333 / 0.371)$ presentan bajos índices de centralidad de relevancia. Por tanto, los jefes de Gabinete del PP han tenido contactos más influyentes o vecinos con una buena centralidad, lo que refleja su mayor proximidad al presidente que sus homólogos socialistas.

Por otra parte, la medición del grado de cohesión y del nivel de centralización de la red gubernamental en distintos periodos nos proporciona una tipología de gabinetes de acuerdo a estos dos criterios, lo que nos permite distinguir entre diferentes gabinetes muy cohesionados (con distintos niveles de centralización alrededor de determinadas figuras como el presidente del Gobierno, el vicepresidente o el jefe del Gabinete) y gabinetes poco cohesionados y más descentralizados.

TABLA 5 .

Medidas de centralidad y clustering de la Presidencia del Gobierno

\begin{tabular}{lccccc}
\hline \multicolumn{1}{c}{ Actor } & $\begin{array}{c}\text { Centralidad } \\
\text { de cercanía } \\
\text { (closeness) }\end{array}$ & $\begin{array}{c}\text { Centralidad } \\
\text { armónica } \\
\text { (harmonic) }\end{array}$ & $\begin{array}{c}\text { Centralidad } \\
\text { de } \\
\text { intermediación } \\
\text { (betwenness) }\end{array}$ & $\begin{array}{c}\text { Coeficiente } \\
\text { de } \\
\text { agrupamiento } \\
\text { (clustering) }\end{array}$ & $\begin{array}{c}\text { Centralidad } \\
\text { de relevancia } \\
\text { (eigenvector) }\end{array}$ \\
\hline Gabinete González/Guerra/Dorado & & & & \\
\hline Felipe González & 0.553 & 0.608 & 72.0 & 0.2 & 0.168 \\
\hline Alfonso Guerra & 0.866 & 0.923 & 255.0 & 0.090 & 1.0 \\
\hline Roberto Dorado & 0.577 & 0.685 & 21.5 & 0.236 & 0.873 \\
\hline $\begin{array}{l}\text { Francisco Fdez. } \\
\text { Marugán }\end{array}$ & 0.509 & 0.570 & 1.0 & 0.7 & 0.701 \\
\hline Virgilio Zapatero & 0.530 & 0.596 & 26.83 & 0.4 & 0.185 \\
\hline
\end{tabular}




\begin{tabular}{|c|c|c|c|c|c|}
\hline Actor & $\begin{array}{l}\text { Centralidad } \\
\text { de cercanía } \\
\text { (closeness) }\end{array}$ & $\begin{array}{l}\text { Centralidad } \\
\text { armónica } \\
\text { (harmonic) }\end{array}$ & $\begin{array}{c}\text { Centralidad } \\
\text { de } \\
\text { intermediación } \\
\text { (betwenness) }\end{array}$ & $\begin{array}{c}\text { Coeficiente } \\
\text { de } \\
\text { agrupamiento } \\
\text { (clustering) }\end{array}$ & $\begin{array}{l}\text { Centralidad } \\
\text { de relevancia } \\
\text { (eigenvector) }\end{array}$ \\
\hline
\end{tabular}

\section{Gabinete González/Serra/Dorado/Zabalza}

\begin{tabular}{lccccc}
\hline Felipe González & 0.525 & 0.579 & 20.0 & 0.5 & 0.367 \\
\hline Narcís Serra & 0.807 & 0.880 & 150.0 & 0.091 & 1.0 \\
\hline José E. Serrano & 0.583 & 0.658 & 44.0 & 0.178 & 0.815 \\
\hline Antoni Zabalza & 0.500 & 0.547 & 1.0 & 0.666 & 0.371 \\
\hline Roberto Dorado & 0.800 & 0.875 & 9.0 & 0.065 & 0.333 \\
\hline
\end{tabular}

\section{Gabinete Aznar/Aragonés}

\begin{tabular}{|c|c|c|c|c|c|}
\hline José M.a Aznar & 0.857 & 0.916 & 446.80 & 0.111 & 1.0 \\
\hline Carlos Aragonés & 0.642 & 0.750 & 90.78 & 0.221 & 0.840 \\
\hline Gabriel Elorriaga & 0.562 & 0.638 & 16.30 & 0.490 & 0.557 \\
\hline Francisco A. Cascos & 0.480 & 0.504 & 35.0 & 0.0 & 0.113 \\
\hline Mariano Rajoy & 0.480 & 0.504 & 35.0 & 0.0 & 0.113 \\
\hline \multicolumn{6}{|c|}{ Gabinete Zapatero/Serrano } \\
\hline $\begin{array}{l}\text { José L. Rodríguez } \\
\text { Zapatero }\end{array}$ & 0.639 & 0.735 & 587.388 & 0.046 & 1.0 \\
\hline José E. Serrano & 0.500 & 0.576 & 204.23 & 0.166 & 0.642 \\
\hline $\begin{array}{l}\text { Alfredo Pérez } \\
\text { Rubalcaba }\end{array}$ & 0.487 & 0.559 & 98.80 & 0.25 & 0.659 \\
\hline $\begin{array}{l}\text { M. }{ }^{a} \text { Teresa Fdez. } \\
\text { de la Vega }\end{array}$ & 0.419 & 0.474 & 111.0 & 0.0 & 0.245 \\
\hline Miguel Sebastián & 0.419 & 0.474 & 111.0 & 0.0 & 0.217 \\
\hline \multicolumn{6}{|c|}{ Gabinete Rajoy/Moragas } \\
\hline Mariano Rajoy & 0.538 & 0.6 & 309.83 & 0.071 & 0.450 \\
\hline Jorge Moragas & 0.603 & 0.761 & 458.58 & 0.033 & 1.0 \\
\hline $\begin{array}{l}\text { Soraya Sáenz de } \\
\text { Santamaría }\end{array}$ & 0.406 & 0.483 & 186.0 & 0.066 & 0.182 \\
\hline $\begin{array}{l}\text { Carmen Martínez } \\
\text { Castro }\end{array}$ & 0.360 & 0.397 & 34.0 & 0.0 & 0.113 \\
\hline Álvaro Nadal & 0.301 & 0.362 & 67.0 & 0.0 & 0.055 \\
\hline
\end{tabular}

Fuente: gráfica Gephi.

De acuerdo con los indicadores, el mayor grado de cohesión y compactibilidad y el menor índice de modularidad $(0,261)$ lo presenta la Presidencia del Gobierno en la etapa de Aznar (gráfico 2). En este periodo, el Gabinete estaba formado en sus puestos directivos por el grupo creado en torno al propio Aznar y a FAES: Gabriel Elorriaga, 
Baudilio Tomé, Alfredo Timermans, etc. [Aragonés]. Solo algunos departamentos, como Internacional y Defensa o Seguridad, eran dirigidos por personas ajenas a este grupo, aunque sus directores fueran conocidos de Aznar [Aznar]. Este mayor nivel de cohesión alrededor del presidente tiene su correspondencia con mayores índices de densidad $(0,152)$ y mayores índices promedio de vínculos de los nodos o actores $(5,459)$ de todas las redes gubernamentales analizadas. También tiene su impacto en el elevado índice de conectividad, que mide la centralización del poder alrededor de uno de los actores $(0,602)$. Comparativamente, Aznar ha sido el presidente con mayores índices de centralidad respecto al conjunto de sus colaboradores: 0.857 en centralidad de cercanía — closeness centrality — y 0.916 de centralidad armónica — harmonic closeness centrality-.

GrÁfico 2.

Gabinete cohesionado y Centralizado alrededor del PResidente AzNAR, I996-2004

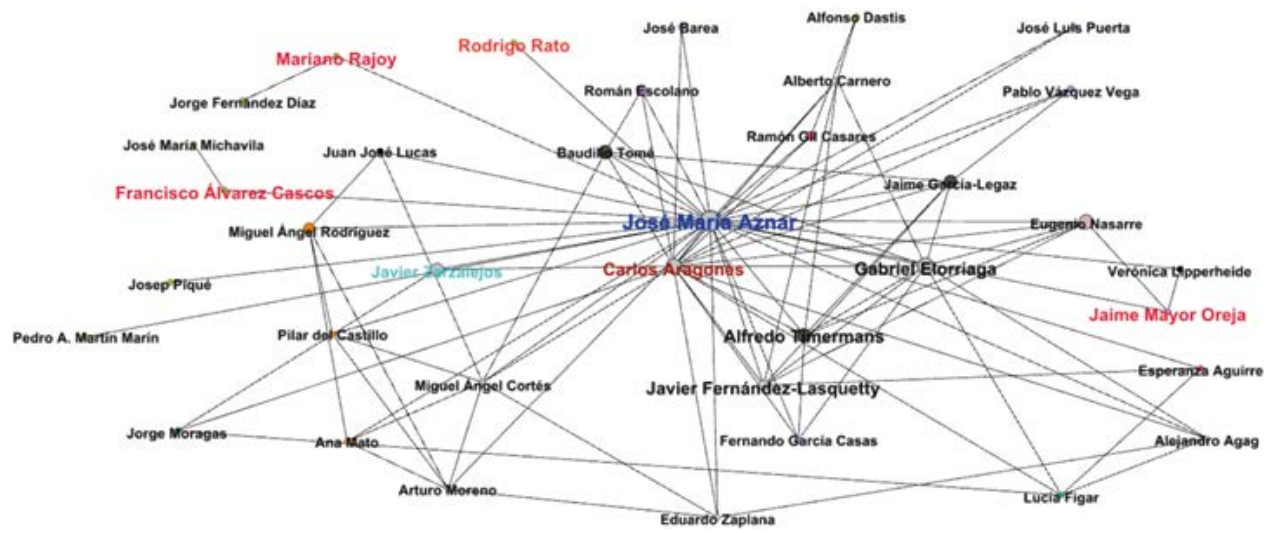

Fuente: gráfico Gephi. Elaboración propia a partir de las entrevistas con diferentes miembros del Gabinete.

Una elevada cohesión presentaba la red gubernamental de Moncloa en la primera etapa de González, con Guerra como eje central que proporcionaba una fuerte unidad al equipo de asesores (gráfico 3). El bajo índice de modularidad $(0,305)$ refleja la existencia de una sola comunidad bajo el control del vicepresidente, y tasas muy elevadas de relación entre los actores políticos, tanto en el índice de densidad como en el índice de vínculos promedio, además del mayor índice de conectividad $(0,780)$ de todo el periodo en estudio. La centralidad de cercanía (0.866) y armónica (0.923) de Guerra solo pueden compararse a las del presidente Aznar; lo mismo cabe señalar de su transitividad, puesto que su coeficiente de clustering o agrupamiento supera al de cualquier presidente en ejercicio en el periodo analizado (0.090).

Una tercera variante de este primer modelo de Gabinete y red gubernamental altamente cohesionada, aunque en un menor grado, es el caso de Rajoy con Moragas (gráfico 4). El Gabinete quedó nucleado alrededor de su propio director, quien gozó de cierta autonomía en el nombramiento de sus colaboradores: muchos procedían de su 
GrÁFICO 3.

GABINETE COHESIONADO Y CENTRALIZADO ALREDEDOR DEL VICEPRESIDENTE: GONZÁLEZ-GueRRA, I982-I99I

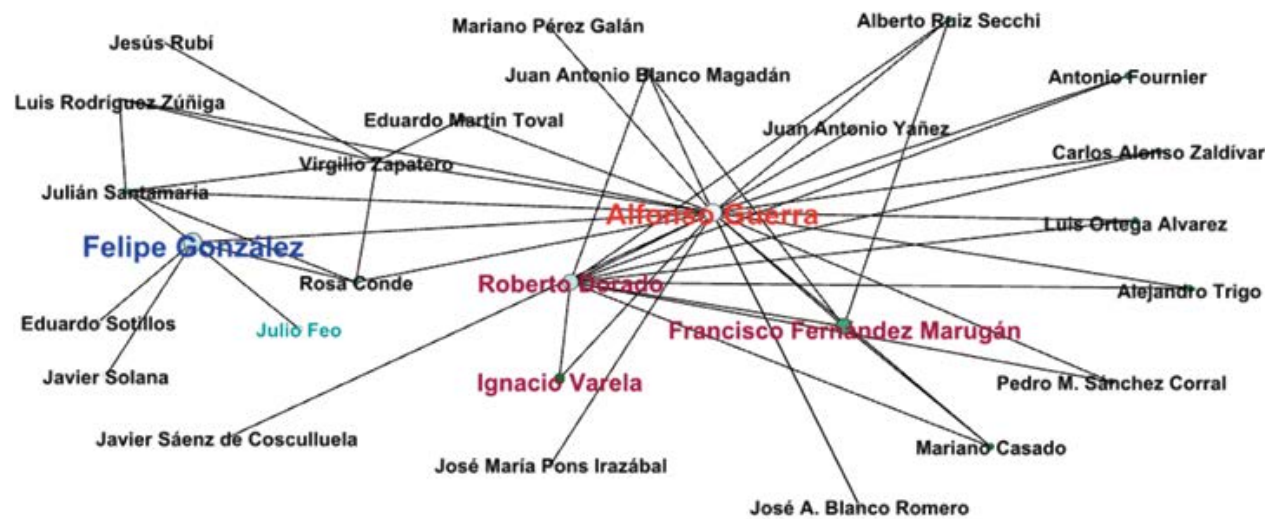

Fuente: gráfico Gephi. Elaboración propia a partir de las entrevistas con diferentes miembros del Gabinete.

GrÁFICO 4.

GABINETE COHESIONADO Y CENTRALIZADO ALREDEDOR DEL JEFE DEL GABINETE: RAJOY, 2O I I-2O I 8

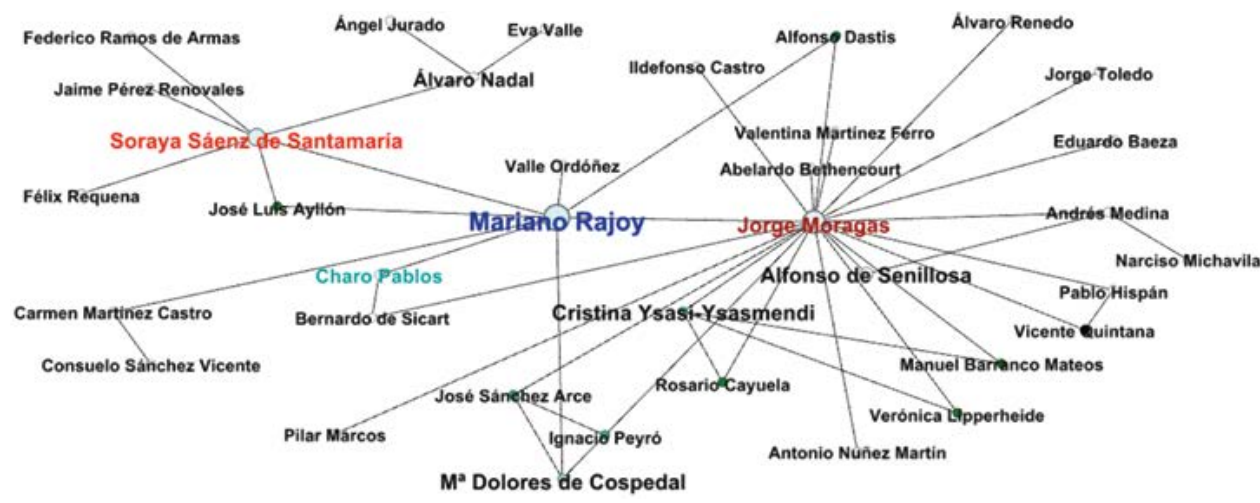

Fuente: gráfico Gephi. Elaboración propia a partir de las entrevistas con diferentes miembros del Gabinete.

equipo de trabajo en la oposición como Valentina Martínez Ferro o Abelardo Bethencourt, y otros como Alfonso de Senillosa, Eduardo Baeza, Sergio Ramos Acosta, Pablo Hispán, Vicente Quintana, etc. Comparativamente, Moragas ha sido el jefe del Gabinete con una mayor centralidad de intermediación (458.58) de todos los directores estudiados y con coeficientes más elevados de clustering y de centralidad de relevancia - eigenvector centrality_ _ es decir, de centralidad de vector propio, que permite identificar al actor con contactos más influyentes o con vecinos que también gozan de una buena centralidad. 
Esta alta centralidad de intermediación es importante pero la posición de Moragas ha sido más débil como eje estructurador que en los casos anteriores, en los que el Gabinete ha estado muy controlado por el presidente o vicepresidente, como muestran el índice de conectividad (0,586, inferior a periodos anteriores) y las medidas de cohesión o de densidad de la red, que reflejan la existencia de subcomunidades fuera del control del jefe del Gabinete, cuya autoridad queda circunscrita solo a los miembros del Gabinete: el índice de modularidad es elevado $(0,467)$ y bajos los índices de densidad $(0,076)$ o el índice promedio de vínculos $(2,67)$.

A diferencia de los distintos ejemplos anteriores, el segundo gran modelo de Gabinete es de carácter descentralizado, con más de un centro sobre el que pivota la red gubernamental. El Gabinete está menos cohesionado y se ha formado por aluvión, mediante la incorporación de colaboradores de diversas procedencias: personal de confianza del presidente, del propio jefe de Gabinete o de otros dirigentes del partido gubernamental (gráfico 5). Los directores de departamento con Zapatero son ejemplos de este proceso de reclutamiento [Serrano], con algunos colaboradores directamente vinculados al presidente (Vidal Zapatero, Marifé Santiago Bolaños, Fernando Magro, etc.) y otros asesores pertenecientes a la órbita del director del Gabinete, de Rubalcaba o cercanos a otros líderes del partido (Enrique Guerrero, Ludolfo Paramio, Andrés Ortega, etc.).

Gráfico 5.

Gabinete POCO COHESIONADO Y DESCENTRALIZAdo: ZAPATERo, 2004-20 I I

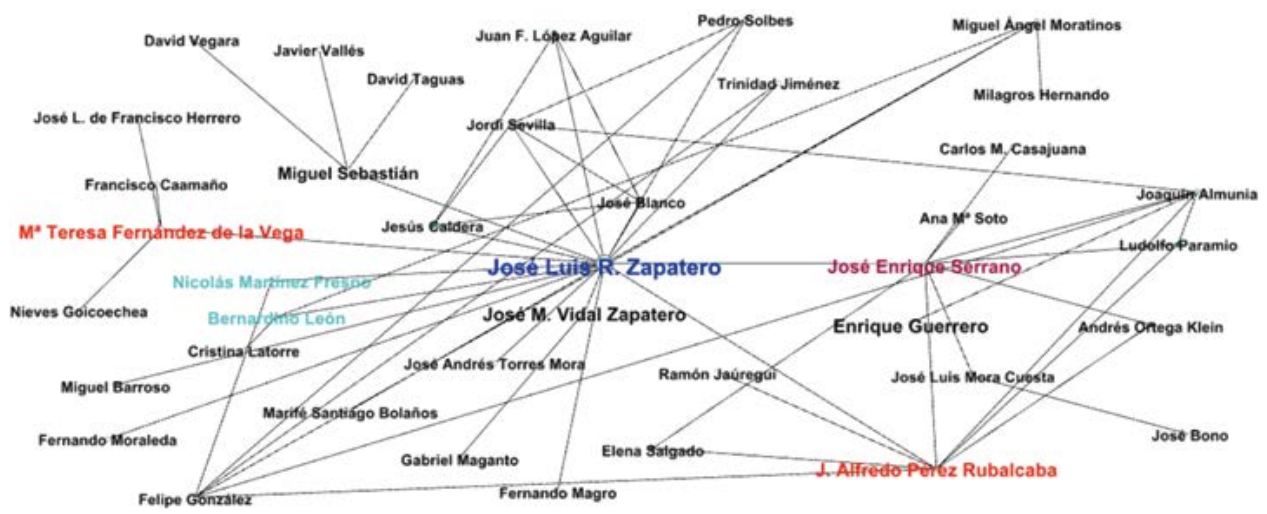

Fuente: gráfico Gephi. Elaboración propia a partir de las entrevistas con diferentes miembros del Gabinete.

Esta estructura reticular descentralizada se refleja en el índice más elevado de modularidad de todas las redes gubernamentales estudiadas $(0,540)$, que implica baja cohesión y un bajo índice de conectividad o centralización, pues ningún actor o nodo ejerce como un claro componente principal $(0,353)$. En este punto, nuestro análisis confirma los resultados de algunos estudios previos que han hallado que la «estructura de poder latente» en el Gobierno de Zapatero desarrolló menores vínculos que 
la estructura de las redes gubernamentales en el Gobierno de Rajoy (Villena y Aldeguer, 2017). Además, destaca el carácter periférico del núcleo dirigente de José Enrique Serrano en el PSOE, a diferencia del carácter central que tienen Jorge Moragas o José Luis Ayllón en el entramado de poder del Gobierno del Partido Popular (ibid..: 79-80). En este punto, su análisis y el nuestro coinciden. Asimismo, coincide con el análisis de que «el entorno presidencial de Zapatero tuvo una organización más horizontal que la de Rajoy, que ha diseñado un Gabinete más centralizado y con funciones que antes estuvieron desempeñadas por organismos diferentes» (Paniagua, 2016: 548 , n. 25).

Una variante de este modelo de Gabinete más descentralizado y menos cohesionado es el del vicepresidente Narcís Serra, con Dorado aún de director del Gabinete (gráfico 6). En su periodo inicial, la red presenta una conectividad media baja $(0,566)$ y una elevada medida de presencia de distintas subcomunidades $(0,472)$ y, por tanto, una baja cohesión. Esta red experimentó un proceso de centralización por etapas, por lo que podrían usarse distintos indicadores para cada una, manteniéndose en 1991 el jefe del Gabinete anterior (Dorado) y varios directores de departamento (Zaldívar, Sánchez Corral, Pérez Galán o Blanco Romero). En una segunda fase, entre 1993 y 1995, todos fueron sustituidos, si bien la dimisión de Serra en 1995 abortó el proceso de control del Gabinete que había emprendido [Serrano].

Gráfico 6.

Gabinete poco cohesionado y descentralizado: GonZÁlez-SERra, I99I-I 995

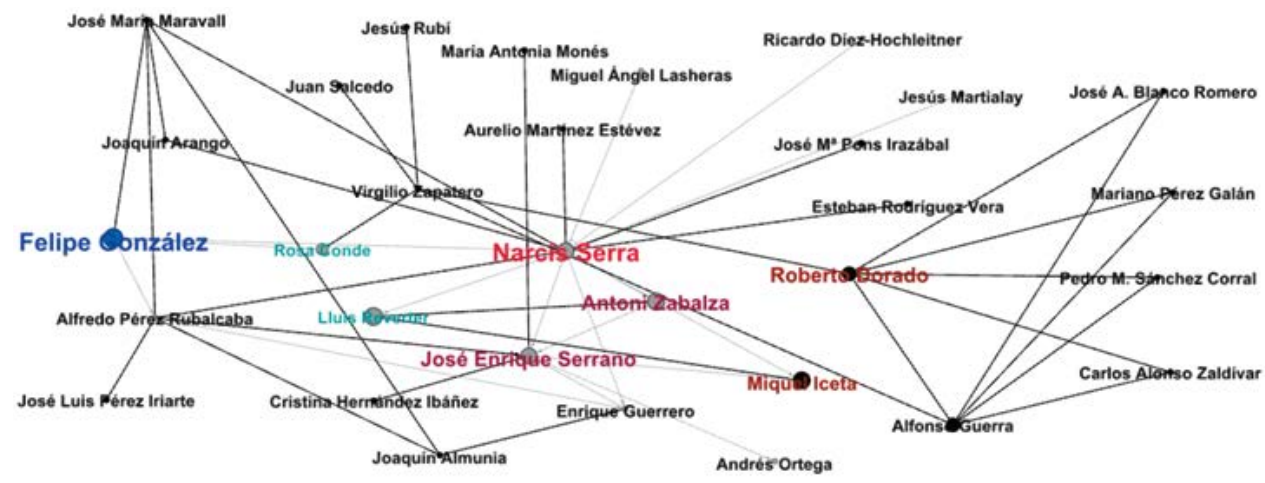

Fuente: gráfico Gephi. Elaboración propia a partir de las entrevistas con diferentes miembros del Gabinete.

\section{CONCLUSIONES}

El estudio realizado presenta una aproximación a una figura clave del poder ejecutivo en Espańa, el jefe del Gabinete del presidente del Gobierno, y arroja algunas conclusiones preliminares. Primero, se ha constatado el afianzamiento de un claro perfil político de esta figura, a diferencia de otros países donde pesa más su carácter 
funcionarial, así como su vinculación con dirigentes de carreras políticas previas que han dotado de una amplia experiencia a quienes han desempeñado el cargo. En segundo lugar, se ha mostrado que la construcción de esta figura institucional se ha producido en disputa con otros actores gubernamentales, como los vicepresidentes, los secretarios generales de Presidencia o los propios ministros. En tercer lugar, la investigación desarrollada permite concluir, especialmente a partir de las entrevistas en profundidad, que el jefe del Gabinete desempeña dos funciones primordiales, que constituyen la base de su poder formal e informal. Por un lado, la función de gatekeeper, debido a su fuerte «poder de exclusión». Por otro, la función de brokering, debido a su gran "poder de conexión», como eje del entorno presidencial. El análisis de esta última función en distintos gabinetes nos ha permitido medir su nivel real de poder $y$ diferenciar el peso político de los distintos ocupantes del cargo a partir de distintos indicadores. Se confirma así la hipótesis (1) del aumento progresivo de la centralidad de esta figura en términos de intermediación política (brokering power) en el sistema político español, y la hipótesis (2) de la tradición del partido gubernamental, ya que este poder de "conectar», como muestran las técnicas de ARS, es distinto según el partido en el Gobierno. Ello ha generado dos tradiciones diferentes de proximidad y confianza entre el presidente y su jefe de Gabinete (hipótesis 2) que se diferencian por el partido gubernamental.

Este tipo de estudios debería contribuir a impulsar una agenda de investigación sobre la distribución del poder en el entorno del presidente del Gobierno y sobre la interacción entre algunos de los principales órganos que forman el core executive en España, y sentar algunas bases para incorporar el caso español en el marco del estudio comparado de las oficinas presidenciales en las democracias occidentales, una área de trabajo en la que, con la excepción de Estados Unidos, aún encontramos graves carencias, no solo en nuestro país, sino en la mayoría de los de nuestro entorno, por las lógicas dificultades que presentan este tipo de investigaciones.

\section{AGRADECIMIENTOS}

Los autores desean expresar su agradecimiento a los evaluadores de la revista por sus comentarios y sugerencias a una versión preliminar de este artículo. Asimismo, quieren hacer constar que el trabajo se cerró en abril de 2018, antes del cambio de Ejecutivo, por lo que solo han podido añadirse unas breves referencias al recién nombrado jefe de Gabinete del presidente Pedro Sánchez.

\section{Referencias}

Blair, Tony. 2010. A Journey. Londres: Hutchinson.

Calvo Sotelo, Leopoldo. 1990. Memoria viva de la transición. Barcelona: Plaza y Janés. 
Cohen, David B., Karen M. Hult y Charles E. Walcott. 2012. «The Chicago Clan: The Chiefs of Staff in the Obama White House», Social Science Quarterly, 93 (5): 1101-1126. Disponible en: https://doi.org/10.111/j.1540-6237.2012.0019.x.

Cohen, David B. Karent M. Hult y Charles E. Walcott. 2016. «White House Evolution and Institutionalization: The Office of Chief of Staff since Reagan», Presidential Studies Quarterly, 46 (1): 4-29. Disponible en: https://doi.org/10.1111/ psq. 12249 .

Colino, César e Ignacio Molina. 2005. "National Governments and the EU», en Peter van der Hoek (ed.), Handbook of Public Administration and Policy in the European Union. Nueva York: Dekker. Disponible en: https:/doi.org/10.1201/b15745.ch12.

Colino, César e Ignacio Molina. 2007. «The Role of National Executives: Changing Capacities and Ambivalent Effects on Democracy», en Ronald Holzhacker y Erik Albaek (eds.), Europeanization and Democratic Governance: Opinion Formation, Interest Intermediation, Decision-Making and National Parliamentary Scrutiny in the EU Member States. Cheltenham: Elgar.

Ferguson, Niall. 2018. The Square and the Tower: Networks and Power. Nueva York: Penguin.

Gabinete de la Presidencia del Gobierno Español. (S. f.) [1982]. Estudio-propuesta de la estructura y funciones de la Presidencia del Gobierno [multicopiado].

Gabinete de la Presidencia del Gobierno Español. (S. f.) [1993]. ¿Qué gabinete queremos? [multicopiado].

Hanneman, Robert y Mark Riddle. 2005. Introduction to Social Network Methods. Riverside: University of California.

Heywood, Paul e Ignacio Molina. 1997. «La présidentialisation du système espagnol: La Moncloa», Revue française d'administration publique, 83: 447-458. Disponible en: https://doi.org/10.1007/978-1-349-62797-4_7.

Heywood, Paul e Ignacio Molina. 2000. «A Quasi-Presidential Premiership: Administering the Executive Summit in Spain", en B. Guy Peters, R. A. W. Rhodes y Vincent Wright (eds.), Administering the Summit. Administration of the Core Executive in Developed Countries. Nueva York. St. Martin's Press.

Inácio, Magna y Mariana Llanos. 2015. «The Institutional Presidency from a Comparative Perspective: Argentina and Brazil since the 1980s», Brazilian Political Science Review, 9 (1): 39-64. Disponible en: https://doi.org/10.1590/1981-38212014000200002.

Kadushin, Charles. 2012. Understanding Social Networks: Theories, Concepts, and Findings. Nueva York: Oxford University Press.

Lanzaro, Jorge. 2016. «El centro presidencial en Uruguay: 2005-2015», Revista Uruguaya de Ciencia Politica, 25 (2): 121-142.

Lanzaro, Jorge (ed.). 2018. Centro presidencial: Presidencias y centros de gobierno en América Latina, Estados Unidos y Europa. Madrid: Tecnos.

Molina, Ignacio. 1998. La cima quasi-presidencial de un sistema parlamentario de gobierno: estructura y funcionamiento de Moncloa [manuscrito], Harvard University, Department of Government. 
Molina, Ignacio, Oriol Homs y César Colino. 2018. «Country Report Spain», en Bertelsmann Stiftung (ed.), Sustainable Governance Indicators 2017. Policy Performance and Governance Capacities in the OECD. Gütersloh: Bertelsmann Stiftung. Disponible en: www.sgi-network.org/docs/2017/country/SGI2017_Spain.pdf.

Müller-Rommel, Ferdinand. 2008. «Prime Ministerial Staff in Post-Communist Central and Eastern Europe: A Role Assessment by Cabinet Ministers», Journal of Communist Studies and Transition Politics, 24 (2): 256-271. Disponible en: https:// doi.org/10.1080/13523270802003095.

Olías, Blanca. 1994. "Los Gabinetes de los Presidentes del Gobierno en España», Politica y Sociedad, 16: 257-272.

Ortega, Luis. 1991. «El Gabinete del Presidente del Gobierno», Documentación Administrativa, 226: 199-243.

Paniagua, Juan Luis. 2016. «La estructura presidencial del Gobierno de España», en César Colino, Jaime Ferri Durá, José A. Olmeda, Paloma Román Marugán y Josefa Rubio Lara (eds.), Ciencia y politica: Una aventura vital. Libro homenaje a Ramón Cotarelo. Madrid: UNED.

Paniagua, Juan Luis. 2018. «La Moncloa: una estructura presidencial para el Gobierno de España, 1978-2015», en Jorge Lanzaro (ed.), Centro presidencial: Presidencias y centros de gobierno en América Latina, Estados Unidos y Europa. Madrid: Tecnos.

Pfiffner, James P. 1993. "The President's Chief of Staff: Lessons Learned», Presidential Studies Quarterly, 23 (1): 77-102.

Pfiffner, James P. 2011. «Decision Making in the Obama White House», Presidential Studies Quarterly, 41 (2): 244-262. Disponible en: https://doi.org/10.1111/ j.1741-5705.2011.03853.x.

Prats i Català, Joan y Manuel Villoria. 2011. «El apoyo al Alto Gobierno: la coordinación y coherencia gubernamental», en Manuel Arenilla Sáez et al. (eds.), Fortalecimiento del Alto Gobierno: Aproximaciones conceptuales. Caracas: CLAD.

Powell, Jonathan. 2011. The New Machiavelli. How to Wield Power in the Modern World. Londres: Vintage Books.

Prell, Christina. 2012. Social Network Analysis: History, Theory and Methodology. Thousand Oaks, CA: Sage.

Rhodes, Roderick A. W. y Anne Tiernan. 2013. «From Core Executive to Court Politics: From a Bucket of Rice to a Bowl of Jelly», ponencia presentada a la Conferencia Anual de la Political Studies Association (PSA), Cardiff.

Rhodes, Roderick A. W. y Anne Tiernan. 2014a. Lessons in Governing: A Profile of Ministers' Chiefs of Staff. Melbourne: Melbourne University Press.

Rhodes, Roderick A. W. y Anne Tiernan. 2014b. The Gatekeepers. Lessons from Prime Ministers's Chiefs of Staff. Melbourne. Melbourne University Press.

Santolaya Machetti, Pablo. 1991. "La experiencia de los gabinetes políticos en Derecho comparado", Documentación Administrativa, 226: 89-112.

Slaughter, Anne-Marie. 2017. The Chessboard and the Web: Strategies of Connection in a Networked World. New Haven: Yale University Press. 
Sullivan, Terry (ed.). 2004. The Nerve Center. Lessons in Governing from White House Chiefs of Staff. College Station, TX: Texas A\&M Press.

Tiernan, Anne y James P. Pfiffner. 2014. "Chiefs of Staff to Presidents and Prime Ministers: A Comparative Perspective», ponencia presentada a la Conferencia Anual de la American Political Science Association (APSA), Washington, D.C.

Truswell, Emma y David Atkinson. 2011. Supporting Heads of Government. A Comparison across Six Countries. Londres: Institute for Government.

Van Biezen, Ingrid y Jonathan Hopkin. 2005. "The Presidentialization of Spanish Democracy: Sources of Prime Ministerial Power in Post-Franco Spain», en Thomas Poguntke y Paul Webb (eds.), The Presidentialization of Politics: A Comparative Study of Modern Democracies. Oxford: Oxford University Press. Disponible en: https://doi.org/10.1093/0199252017.003.0005.

Villena Oliver, Andrés y Aldeguer Cerdá, Bernabé. 2017. «La importancia de los gobernantes invisibles en la democracia. Un estudio de la «estructura de poder latente» de dos Gobiernos en España (2004 y 2012)», Revista Española de Ciencia Politica, 45: 67-94. Disponible en: https://doi.org/10.21308/recp.45.03.

Virgala Foruria, Eduardo. 1994. «La organización interna del poder ejecutivo en los Estados Unidos: el presidente, el gabinete y la presidencia institucionalizada", Revista de Estudios Politicos, 83: 137-188.

Whipple, Chris. 2017. The Gatekeepers. How the White House Chiefs of Staff Define Every Presidency. Nueva York: Crown.

\section{ANEXOS}

Entrevistas realizadas (citadas entre corchetes)

Carlos Aragonés, 2004

José M. a Aznar, 2005

Roberto Dorado, 2003

Gabriel Elorriaga, 2004

Javier Fernández Lasquetty, 2004

Manuel Ortiz, 2003

José Enrique Serrano, 2007

\section{Nota metodológica}

En la tabla 4 se recogen medidas globales a nivel de la red gubernamental, como los índices de densidad (número de vínculos entre los actores de una red respecto a los potencialmente posibles), modularidad (nivel de división de una red en módulos, grupos o comunidades), grado medio (número medio de vínculos que tiene un actor) y conectividad (proporción de actores conectada al actor principal). En la tabla 5 se 
integran distintas medidas, a nivel de actores, de centralidad y clustering: la centralidad de cercanía (closeness centrality), esto es, distancia promedio al resto de la red, lo que supone que el actor que está más cerca de todos los demás actores es el más central; la centralidad armónica, entendida como la ponderación de los valores de cercanía para considerar los enlaces directos e indirectos de cada actor; la centralidad de intermediación (betweenness centrality), el número de caminos geodésicos que conectan cualquier par de nodos de la red. Identifican los actores «puente», también denominados gatekeepers (o porteros), por los que más actores deben pasar para hacer sus conexiones indirectas o no adyacentes, que nos permite identificar a los actores con una mayor capacidad de controlar el flujo y la difusión de información y mensajes en la red gubernamental; el coeficiente de agrupamiento o clustering, una medida de transitividad de cada nodo o actor de la red, que identifica a los actores con otros contactos que tienen relaciones entre sí como subgrupo o subcomunidad, y, finalmente, la centralidad de relevancia (o centralidad de vector propio — eigenvector centrality—), que indica la influencia de un actor o nodo de la red. Considera central a aquel actor que tiene más vecinos también centrales, puesto que los actores unidos a actores importantes tendrán una «relevancia» mayor que otros con el mismo número de enlaces pero a actores menos importantes.

Presentado para evaluación: 24 de abril de 2018.

Aceptado para publicación: 10 de octubre de 2018.

\section{ANTONIO GARRIDO}

agarrido@um.es

Profesor de Ciencia Política y de la Administración y vicedecano en la Facultad de Derecho de la Universidad de Murcia. Doctor en Ciencias Políticas por la Universidad Complutense de Madrid y licenciado en Derecho. Es autor de varios libros sobre diseño constitucional e instituciones políticas, elecciones y comunicación política.

\section{ANTONIA MARTÍNEZ}

antoniam@um.es

Catedrática de Ciencia Política y de la Administración en la Universidad de Murcia. Ha sido, previamente, profesora titular en la Universidad de Salamanca. Es maestra en Estudios Latinoamericanos por la Universidad Nacional Autónoma de México y doctora en Ciencias Políticas y Sociología por la Universidad Complutense de Madrid. Fue asesora en el Gabinete del Presidente del Gobierno de España de 1998 a 2004. 